\title{
Combined acromioclavicular joint dislocation and coracoid avulsion in an adult
}

\author{
Monappa Naik, ${ }^{1}$ Sujit Kumar Tripathy, ${ }^{2}$ Saumitra Goyal, ${ }^{1}$ Sarath K Rao ${ }^{1}$
}

${ }^{1}$ Department of Orthopaedics, KMC, Manipal, Manipal, India ${ }^{2}$ Department of Orthopaedics, All India Institute of Medical Sciences, Bhubaneswar, Odisha, India

\section{Correspondence to}

Dr Sujit, Kumar Tripathy, sujitortho@yahoo.co.in

Accepted 1 May 2015

\section{SUMMARY}

Avulsion fracture of coracoid process with acromioclavicular joint dislocation is extremely rare. We report a case of coracoid avulsion with acromioclavicular disruption in a 24-year-old man who sustained injuries in a road traffic accident. Although acromioclavicular (AC) dislocation was obvious from an initial radiograph, coracoid avulsion was picked up in a CT scan. Open reduction and internal fixations of the coracoid with a $4 \mathrm{~mm}$ cannulated screw, an AC joint with two K-wires and an anchor suture, resulted in rapid recovery. The patient had complete range of shoulder movements at the end of 3 months and he resumed his professional activities. After 1 year, he had normal shoulder movement without any functional limitations.

\section{BACKGROUND}

Coracoid process (CP) fractures constitute 3-13\% of scapular fractures, and scapular fracture merely constitutes $1 \%$ of all fractures. ${ }^{1}$ Avulsion fracture of $\mathrm{CP}$ with acromioclavicular joint (AC) dislocation is even rarer and has been scarcely reported in the literature. $^{2-11}$ These combined injuries pose many challenges to the trauma surgeon. Orthopaedic surgeons often fail to diagnose $\mathrm{CP}$ fracture in plain radiographs when an obvious $\mathrm{AC}$ dislocation is associated. This is because of marked shortening and projection of $\mathrm{CP}$ over the acromion or blade of scapula. ${ }^{3}$ The injury mechanism involved in these combined injuries remains controversial and there is no definite consensus on its treatment. The heterogeneity of case reports with hypothetical explanations of the injury mechanism and treatment have relegated these combined injuries to a controversial state. In this report, we present a case of avulsion fracture of $\mathrm{CP}$ with $\mathrm{AC}$ dislocation in an active young man, and briefly present a short review of the literature.

\section{CASE PRESENTATION}

A 24-year-old man, a manual labourer, sustained injury to his left shoulder in a road traffic accident. He was presented to our clinic 2 days later with a prominence in the left shoulder. His shoulder abduction on the affected side was limited to $60^{\circ}$ and flexion $80^{\circ}$. Cross-body adduction was painful. $\mathrm{AC}$ joint and $\mathrm{CP}$ were tender on palpation. Clinically, AC dislocation was suspected. Radiographs revealed AC disruption with suspicion of CP avulsion (figure 1). CT scan with threedimensional reconstruction was advised to delineate the fracture and dislocation (figure 2). A displaced $\mathrm{CP}$ fracture was identified and the $\mathrm{AC}$ was

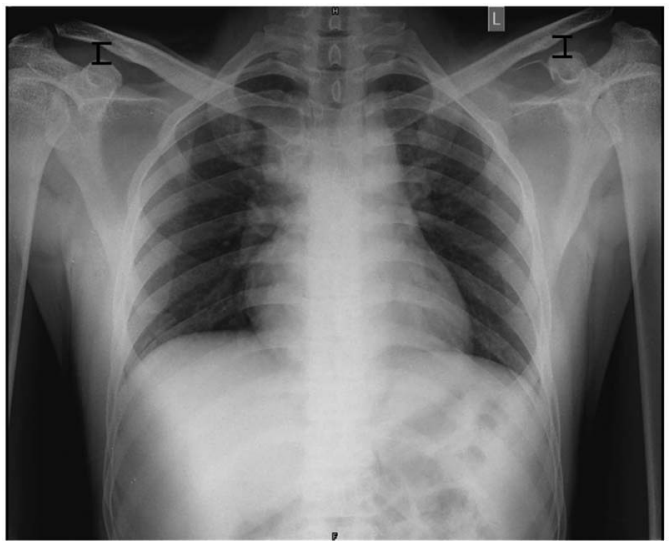

Figure 1 Plain radiograph showing acromioclavicular dislocation with coracoid process (CP) fracture on the left. The distance between $\mathrm{CP}$ and lateral end clavicle is equal on both sides indicating that CC ligament is intact.

found displaced superiorly (Rockwood classification grade III; figure 3).

Open reduction and internal fixation was planned. Intraoperatively, we found the coracoclavicular (CC) ligament to be intact. After reduction of the displaced CP, we found that the lateral articular end of the clavicle was completely reduced and the AC joint was in place. The CP was temporarily fixed with a K-wire and a cannulated $4 \mathrm{~mm}$ screw with washer was inserted through it. The AC joint was fixed with two K-wires inserted from the

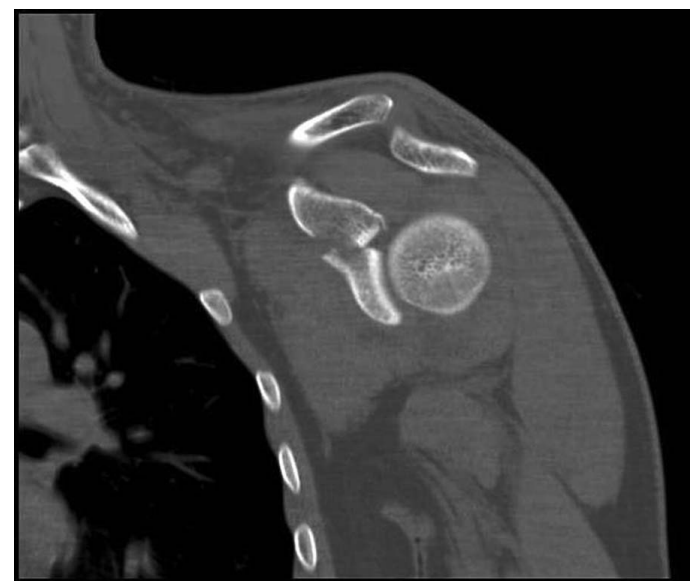

Figure 2 Coronal cut section of CT scan shows the extent of the combined injury; the fracture line involving the coracoid process has extended up to the superior part of glenoid and acromioclavicular joint is superiorly dislocated. 
Figure 3 Three-dimensional CT clearly depicts the extent of coracoid process fracture and acromioclavicular joint dislocation.

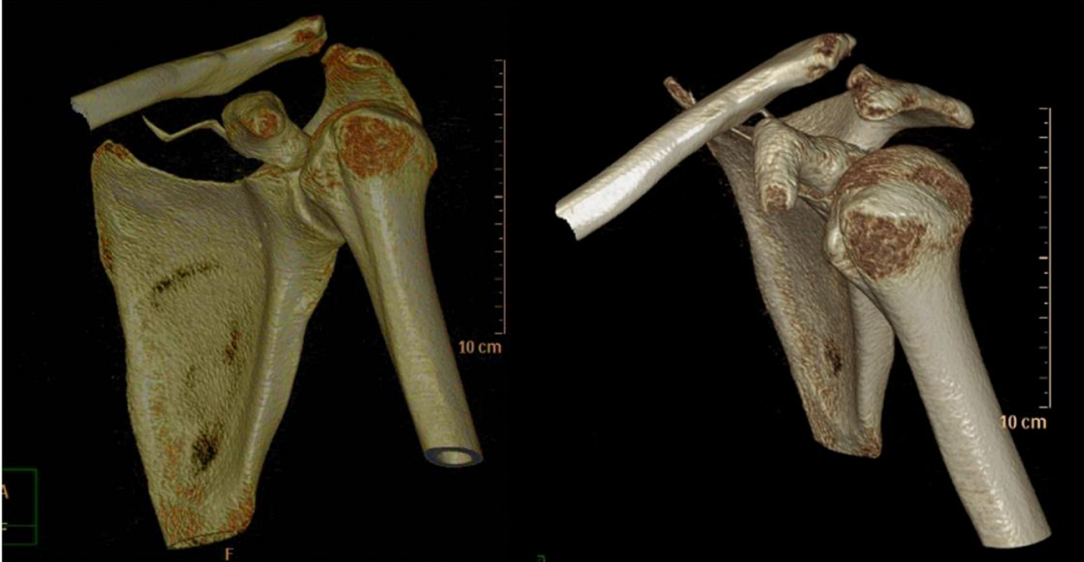

acromion process. It was further stabilised with an anchor suture (Mitek), which was fixed to the base of CP posterior and medial to the fracture line. A drill hole was made in the lateral portion of the clavicle and the sutures were passed through and tied (figure 4).

The arm was rested in a sling for an initial 3 weeks. Pendulum shoulder exercises and active-assisted motions of the shoulder were initiated the day after surgery.

\section{OUTCOME AND FOLLOW-UP}

After 6 weeks, the patient had complete movement of the shoulder joint. The K-wires were removed after 3 months. Radiograph showed healing of both these injuries in the anatomical position (figure 5). The patient resumed his professional activities without functional limitations. At 1-year follow-up, the patient did not have any symptoms and his shoulder joint movements were normal.

\section{DISCUSSION}

Combined CP fracture and $\mathrm{AC}$ dislocation is a rare occurrence in adults. This injury has been reported both in trauma victims and athletes. ${ }^{2-11}$ However, the mechanism of this combined injury still remains controversial. Isolated AC joint dislocation occurs when a cephalad to caudal force is exerted on the acromion by a direct blow to or fall on the shoulder. The AC ligaments are disrupted first, followed by the disruptions of deltoid

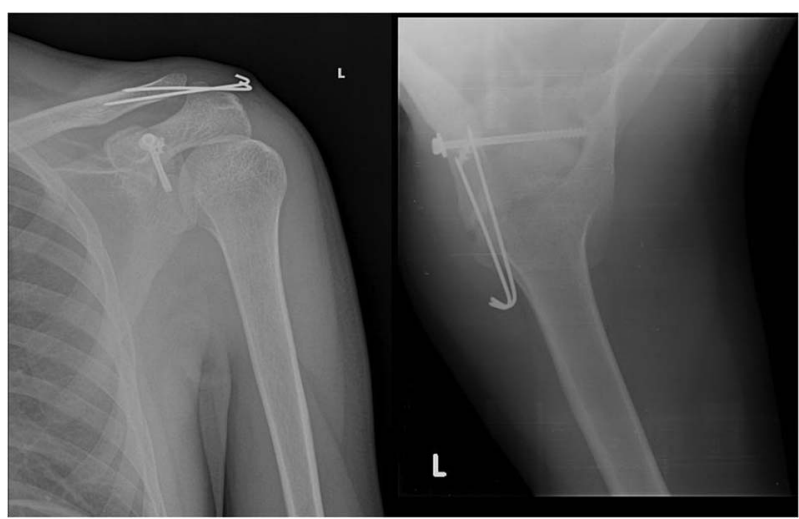

Figure 4 Postoperative anteroposterior and lateral radiographs showing anatomical restorations of coracoid process and acromioclavicular joint with rigid fixations with a lag screw and K-wires +anchor suture (Mitek). and trapezius secondarily. The tearing of the CC ligaments completes this injury with dislocation of the $\mathrm{AC}$ joint. ${ }^{2}$ In adolescents, the CC ligaments are stronger than the unfused CP epiphyseal plate and any injury to the shoulder results in avulsion fracture of the CP epiphyseal plate with an intact ligament. However, in adults, the $\mathrm{CP}$ and clavicle are stronger than the CC ligaments; therefore, almost all Rockwood type III AC joint injuries involve a tear of the CC ligaments rather than a fracture of the CP. The epiphyseal plate of the CP is near its base, and it fuses between 15 and 18 years of age. Hence, any injury to the shoulder region below this age causes disruption of $\mathrm{AC}$ joint with avulsion of the $\mathrm{CP}^{3}$ However, the published cases of fractured CP with AC dislocation have been reported in those aged between 9 and 60 years, with a median of 23.5 years. ${ }^{3}$ At this median age, one would expect the CC ligament to be ruptured rather than a fracture of the $\mathrm{CP}$. At this controversial juncture, we believe that the injury mechanism advocated by Li et $\mathrm{al}^{3}$ is logical and justified. They assumed that the combined force of conjoined tendons and the pectoralis minor muscles is involved in the traumatic mechanism. At first step, a sudden contraction of the conjoined tendons and pectoralis minor muscles (for protection or other reasons) results in fracture of the CP. In the second step, whether the CC ligament remains intact or not depends on the strength of the component residual force along the CC ligaments. A similar injury mechanism might have produced this combined injury in our case.

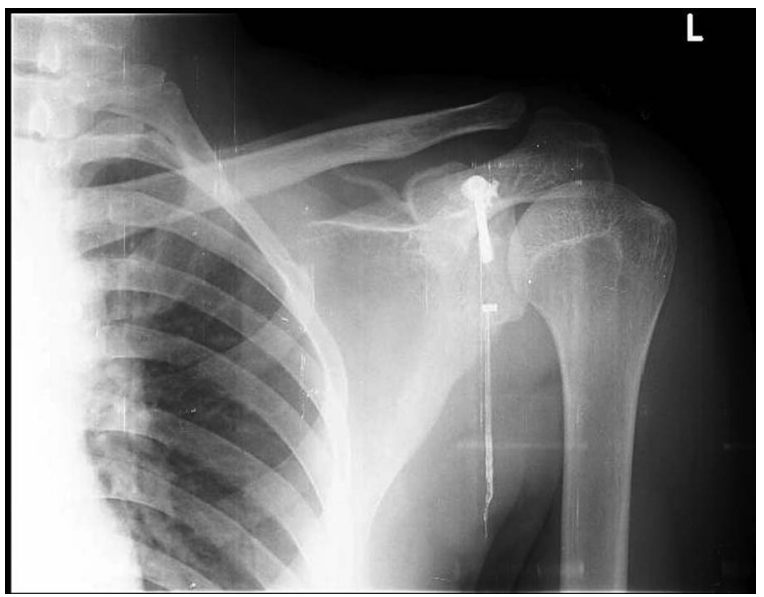

Figure 5 Three months later, the K-wires were removed and radiograph shows healing of both the coracoid process fracture and acromioclavicular dislocation in the anatomical position. 
In a combined injury, the CP fracture is easily overlooked as the attention is drawn towards the most obvious AC joint dislocation. Special radiographic views (axillary and $30^{\circ}$ cephalad view) must be considered to assess the status of CP. ${ }^{911}$ A CT is helpful as it provides a clear picture of both the coracoid fracture and the $\mathrm{AC}$ joint dislocation. ${ }^{9}{ }^{11}$ One may have an idea about the CC ligament injury by measuring the distance between $\mathrm{CP}$ and $\mathrm{AC}$ joint in plain radiography. ${ }^{2} 56$ However, MRI is the best way to assess the continuity of CC ligaments. ${ }^{2} 4$

As per the current literature, there is no difference in the long-term outcomes of patient managed conservatively or surgically in these combined injuries. ${ }^{2}{ }^{11}$ However, a few earlier reports have mentioned pain and cosmetic symptoms after conservative management. ${ }^{4} 10$ On the other hand, all reported patients treated surgically recovered fully, except for one reported by Wilber and Evans, who was treated with an unknown surgical method and reported of persistent pain and decreased shoulder motion 1 year postoperatively. ${ }^{13}$ Multiple approaches have been opted for by surgeons to deal with this combined injury; some have opted to address only the AC joint and others have found that surgical reduction of the $\mathrm{CP}$ reduced the AC indirectly. ${ }^{9-13}$ Nevertheless, disrupted CC ligaments should always be repaired or reconstructed for optimal functional outcome whenever associated with these combined injuries. $^{3}$ Ogawa et $a l^{1}$ classified CP fracture (isolated or in combination with $\mathrm{AC}$ dislocation) into two types. In type 1, the fracture locates behind the CC ligament and in type 2, it is located anterior to it. The authors recommended that type 1 injury needs operative intervention to start early physiotherapy and type 2 does not need surgical intervention. For a combined injury, Ogawa et al favoured a single malleolar screw for fixation of the coracoid with concurrent wiring of a fractured clavicle or AC dislocation. They recommended treating concurrent AC dislocation and stable coracoid fracture as simple AC dislocations are treated. A logistic approach is that both these injuries (AC dislocation and CP fracture) should be stabilised in manual labourers or heavy load workers and only one of these injuries may be addressed in patients whose functional demands are less. However, surgical fixation must be performed in all cases to have consistent and predictable results. The AC joint is diaarthrodial and closed reductions have high chances of entrapping the capsule, ruptured fibrocartilagenous disc and detached articular cartilage, resulting in a painful unreduced $\mathrm{AC}$ joint. ${ }^{2} 3$ We believe that rigid stabilisation of both the CP fracture and AC joint dislocation allows early patient rehabilitation. Along with a lag screw for CP fracture, we fixed the AC joint with two stabilisation methods (two $\mathrm{K}$ wires and an anchor suture) that we follow conventionally for fixation of isolated AC joint dislocation. This dual fixation method reduced the pull over the CP through CC ligaments, thus allowing early healing of both the injuries. The patient had complete recovery of function at the end of 1 year.

Even though rare, coracoid process fracture should be suspected in AC joint dislocations in adults. Whenever in doubt, special radiographic views and CTs should be obtained. Surgical fixations of the coracoid process and AC joint provide rigid stability and allow early rehabilitation with excellent functional outcome.

\section{Learning points}

- Coracoid process fracture may be an associated injury in acromioclavicular (AC) joint dislocations.

- In doubtful cases, special radiographic views and CTs should be obtained.

- Both the fractures should be fixed so that early rehabilitation can be started, and doing so usually provides excellent functional outcome.

Contributors MN, SKT and SKR actively managed the patient and collected the data. SKT, MN and SG prepared the initial draft. SKT and SG reviewed the literature. SKR provided intellectual content to the manuscript. All authors have read the manuscript and approved it.

Competing interests None declared.

Patient consent Obtained.

Provenance and peer review Not commissioned; externally peer reviewed.

\section{REFERENCES}

1 Ogawa K, Yoshida A, Takahashi M, et al. Fractures of the coracoid process. J Bone Joint Surg Br 1997;79:17-19.

2 Gunes T, Demirhan M, Atalar AC, et al. A case of acromioclavicular dislocation without coracoclavicular ligament rupture accompanied by coracoid process fracture. Acta Orthop Traumatol Turc 2006;40:334-7.

3 Li J, Sun W, Li G, et al. Fracture of the coracoid process associated with acromioclavicular dislocation: a case report. Orthop Surg 2010;2:165-7.

4 Montgomery SP, Loyd RD. Avulsion fracture of the coracoid epiphysis with acromioclavicular separation. Report of two cases in adolescents and review of the literature. J Bone Joint Surg Am 1977;59:963-5.

5 Wang KC, Hsu KY, Shih $\mathrm{CH}$. Coracoid process fracture combined with acromioclavicular dislocation and coracoclavicular ligament rupture. A case report and review of the literature. Clin Orthop Relat Res 1994;300:120-2.

6 Wilson KM, Colwill JC. Combined acromioclavicular dislocation with coracoclavicular ligament disruption and coracoid process fracture. Am J Sports Med 1989;17:697-8

7 Yu KS, Chan PT, Ngai WK, et al. Coracoid process fracture combined with acromioclavicular joint dislocation and coracoclavicular ligament disruption. Sicot Case-Reports: April 2002

8 Zettas JP, Muchnic PD. Fractures of the coracoids process base in acute acromioclavicular separation. Orthop Rev 1976;5:77-9.

9 Protass JJ, Stampfli FV, Osmer JC. Coracoid process fracture diagnosis in acromioclavicular separation. Radiology 1975;116:61-4.

10 Bernard TN Jr, Brunet ME, Haddad RJ Jr. Fractured coracoid process in acromioclavicular dislocations. Report of four cases and review of the literature. Clin Orthop Relat Res 1983;175:227-32.

11 DiPaola M, Marchetto P. Coracoid process fracture with acromioclavicular joint separation in an American football player: a case report and literature review. Am J Orthop 2009;38:37-40.

12 Wilber MC, Evans EB. Fractures of the scapula. An analysis of forty cases and a review of the literature. J Bone Joint Surg Am 1977;59:358-62.

13 Taga I, Yoneda M, Ono K. Epiphyseal separation of the coracoid process associated with acromioclavicular sprain. A case report and review of the literature. Clin Orthop Relat Res 1986;207:138-41. 
Copyright 2015 BMJ Publishing Group. All rights reserved. For permission to reuse any of this content visit http://group.bmj.com/group/rights-licensing/permissions.

BMJ Case Report Fellows may re-use this article for personal use and teaching without any further permission.

Become a Fellow of BMJ Case Reports today and you can:

- Submit as many cases as you like

- Enjoy fast sympathetic peer review and rapid publication of accepted articles

- Access all the published articles

- Re-use any of the published material for personal use and teaching without further permission

For information on Institutional Fellowships contact consortiasales@bmjgroup.com

Visit casereports.bmj.com for more articles like this and to become a Fellow 